\title{
Patient Relationships and the Personal Physician in Tomorrow's Health System: A Perspective from the Keystone IV Conference
}

\author{
Jack M. Colwill, MD, John J. Frey, MD, Macaran A. Baird, MD, John W. Kirk, MD, \\ and Walter W. Rosser, MD
}

A group of senior leaders from the early generation of academic family medicine reflect on the meaning of being a personal physician, based on their own clinical experiences and as teachers of residents and students in academic health centers. Recognizing that changes in clinical care and education at national and local systems levels have added extraordinary demands to the role of the personal physician, the senior group offers examples of how the discipline might go forward in changing times. Differently organized care such as the Family Health Team model in Ontario, Canada; value-based payment for populations in large health systems; and federal changes in reimbursement for populations can have positive effects on physician satisfaction. These changes and examples of changes in medical student and residency education also have the potential to positively affect the primary care workforce. The authors conclude that, without substantive educational and health system reform, the ability to truly serve as a personal physician and adhere to the values of continuity, responsibility, and accountability will continue to be threatened. (J Am Board Fam Med 2016;29:S54-S59.)

Guest editors' note: This paper was prepared after the G. Gayle Stephens Keystone IV Conference by authors from the oldest generation of conference attendees. It affirms the importance of personal physicians based not on theory, but on lived experience.

Keywords: Doctoring, Family Medicine, Family Physician, Health Care Delivery, Personal Physician, Population Health, Primary Care, Professionalism, Social Justice

Who would think a conference focusing on patient relationships would prove to be an inspirational event? Keystone IV truly was inspirational for us as

\footnotetext{
This article was externally peer reviewed.

Submitted 13 January 2016; revised 26 April 2016; accepted 3 May 2016.

From the Department of Family and Community Medicine, University of Missouri School of Medicine, Columbia (JMC); the Department of Family Medicine and Community Health, University of Wisconsin School of Medicine and Public Health, Madison (JJF); the Department of Family Medicine and Community Health, University of Minnesota, Minneapolis (MAB); the Department of Community and Family Medicine, Dartmouth Medical School, Hanover,

$\mathrm{NH}$ (JWK); and the Department of Family Medicine, Queen's University, Kingston, Canada (WWR).

Funding: none.

Conflict of interest: none declared.

Corresponding author: Jack M. Colwill, MD, Department of Family and Community Medicine, University of Missouri, M226 Medical Sciences Building, DC032.00, Columbia, MO 65212 (E-mail: ColwillJ@health.missouri.edu).
}

we listened to the deeply moving stories and shared beliefs of clinicians and patients about patient relationships being the heart of family medicine. There was also agreement that the role of personal physician is under enormous strain, making the conference both challenging and renewing. In the end we sensed intergenerational and interdisciplinary solidarity in the room.

With a combined total of 240 years of academic and clinical experience since medical school, we 5 were categorized as "the older generation" and, as such, were asked to reflect on the role of the personal physician in today's world. We have had long-term practices and held academic positions. We have watched our patients age with us. They beg us not to retire. For our patients, we are caregivers, healers, advisors, friends, and navigators through a complex system. Our patients are admirable human beings who taught us our craft, offer- 
ing clinical challenges and providing us with the gratification that makes practicing medicine worthwhile. A principal challenge for the present and future, we agree, is to be able to establish and maintain the long-term trusting relationships that have characterized family doctors and our role in health systems and society.

One of us described caring for a family over many decades and then being honored to speak at the patient's funeral. He commented, "Somehow it was the repeated 'episodes' of my involvement over a long period that meant much to the family ... and to me. Such satisfaction/joy will never be realized by our younger colleagues unless they are able to invest themselves in their communities over longer periods of time. Nor will patients and families know the peace and confidence that comes when challenging medical problems are at least partly in the hands of a familiar and trusted clinician."

Another of us described recently caring for 2 long-term patients through terminal hospice care, 1 with bladder cancer and the other with Parkinson disease. He had dealt with their multiple problems over the years and with the assistance of a urologist/ oncologist and a neurologist during their final years. Despite the severity of these illnesses, at no time over the decades had either patient or family physician felt hospitalization was necessary. That long-term trusting relationship seemed to provide a level of care and support that is less likely to occur today, when a typical patient has been seen by an average of 10 different physicians during the last 6 months of life. ${ }^{1}$ For that physician who had assumed responsibility and accountability for integrating care, the sense of accomplishment in caring for each individual and supporting their families was highly gratifying. And for the medical system it could only be viewed as high-value care (quality care at a reasonable cost).

At Keystone, we reflected on what it means to be perceived as one's "personal physician," one who accepts responsibility and accountability over time. $^{2}$ We recognized that a large percentage of Americans do not have a personal physician, and many feel "quick care" meets their needs. With the onset of chronic disease, however, patients' desire for a personal physician who "knows me" blossoms.

We thought about the dissatisfaction felt by physicians across all specialties, and more specifically in primary care. ${ }^{3,4}$ Frustrations lie with methods of reimbursement, electronic health record documentation, administrative and regulatory requirements, and above all with the sense of being handicapped by insufficient time and increasing work in the consultation room-the "hamster wheel" phenomenon. Nevertheless, most studies suggest that we physicians thrive on the gratification that comes from continuing relationships with patients over time. Yet many of us have gradually given up inpatient care to hospitalists and watched primary care fragment further into corporatized "quick care," "urgent care," "emergency care," and "nursing home care" entities. This disruption in continuity reduces the likelihood that patients will develop a meaningful, ongoing relationship with a personal physician. However, we cannot lose sight of the fact that what motivates residents today are the same values that motivated us over our careers. The challenge is to change the systems in which we work to preserve those values. ${ }^{5}$

For us in the latter stage of our professional careers, the reduced workload permits more time for patient visits, hospital visits, and home visits, as well as time to ferret out symptoms. It allows time to seek approaches to understanding and managing patients' problems by searching the literature and having verbal consultations with specialists and colleagues. Having sufficient time reduces the urge to triage patients to specialists and has the potential to decrease duplication, control costs, and avoid conflicting messages to patients. The larger the number of consultants, the greater the dilution of responsibility and accountability.

Obviously, having practices such as ours would leave us paupers in today's productivity-driven feefor-service systems. But could not the savings from avoiding overuse of referrals and hospitalization finance primary care practices of manageable size so we could truly serve as personal physicians for those with multiple problems? A key for us has been to have adequate flexibility in our schedules and a commitment to be personal physicians.

Ontario's Family Health Team model of patient-centered medical homes, serving over 3 million Ontarians, seems to have an organizational and reimbursement structure that fosters continuing relationships and high-quality care. ${ }^{6}$ Patients sign up with a family physician for ongoing care. Physicians have the flexibility to limit their patient panel size. They delegate responsibility to multidisciplinary team members and use E-mail and phone to handle problems rather than being lim- 
ited to physician visits for reimbursement. This model, implemented in 2005, uses a combination of capitation, fees for services, and bonuses. Capitation provides about $60 \%$ of funding. Fees serve to stimulate visits by infants and patients $>70$ years old and motivate hospital, home, and nursing home visits and office procedures. Bonuses motivate population-based prevention and quality measures. This system has the potential to permit the development of high-value care with the personal physician at the center of the process. Preliminary observations suggest high satisfaction among patients, higher physician income, and more gratification for family physicians. Currently, the overall percentage of students matching in family medicine in Canada is $38 \%,{ }^{7}$ and the percentage of Ontario medical students entering family medicine increased from 24\% to $41 \%$ between 2004 and 2015 .

While outcome data from the Family Health Team model have not yet been published, studies from other systems support these approaches. A study from Group Health of Puget Sound showed that reducing patient health maintenance organization panel size and increasing supporting staff was associated with a reduction in emergency department visits and hospitalizations, and physicians and staff were more satisfied with their work. ${ }^{8}$ In another study, smaller primary care practices were found to have lower rates of preventable hospital admissions, ${ }^{9}$ and smaller practices may give clinicians more control over their lives and focus more on value. ${ }^{10}$ Perhaps these smaller practices provide greater continuity with a personal physician. Another recent study showed that a broader scope of family practice is associated with lower costs and hospitalizations. ${ }^{11}$ Today, the movement to direct patient care is proving to be a "disruptive technology," permitting physicians flexibility to manage the size of their practices while having adequate income and more control over their work environment. ${ }^{12}$ Such practices clearly promote the role of personal physician. With correct incentives they may also provide high-value care. The recent announcement by the Center for Medicare and Medicaid Services that they will be moving away from fee-for-service payments toward comprehensive care and case management has the potential to transform practices in a way that would increase practice-based teams, focus less on volume and production, and perhaps have more time to really serve as a personal physician. ${ }^{13}$
National plans for health reform under the $\mathrm{Pa}$ tient Protection and Affordable Care Act are dependent on a strong foundation of primary care provided by personal physicians in interdisciplinary teams. Yet the elephant in the room is the decreasing proportion of physicians who see their role as being "personal" physicians. ${ }^{14}$ While most family medicine graduates will enter primary care, it seems that only about $20 \%$ of internal medicine graduates will do likewise; most subspecialize or become hospitalists. It seems that only about $19 \%$ of all current first-year residents will practice adult primary care, and many of these will not be in settings that emphasize the role of personal physician. Yet we suspect that much of the value from primary care comes from integration and coordination of services over time.

Students increasingly view primary care as an office-based, high-volume, low-relationship form of care with unmanageable demands. Being driven by student debt and concerns of work/life balance, many residency graduates are staffing urgent care clinics or being employed by hospitals to see patients in clinics where they have no on-call responsibilities. In these settings many find themselves governed by corporate demands and administrators with interest only in volume, rather than in designing systems where generalists can fulfill the broader role of a personal physician. Fortunately, increasing demand will also increase the bargaining power of primary care physicians as they negotiate their practices as personal physicians.

It seems to us that the educational programs for students and residents, which we have designed, have not provided them with adequate experiences to fully appreciate the importance of long-term relationships. Yet we believe that strong patient relationships during training have the potential to be real drivers for a selection of primary care. Students in most family medicine clerkships seldom see ambulatory patients more than once. Residents' ambulatory experiences may tend more toward care of patients seeking episodic care and less on continuing relationships. One of us noted, "I shall long remember comments by a family medicine resident who cared for one of my long-term patients during his hospitalization. 'He was such a nice man. Who was he?’ she asked.” She had spent so much time treating the disease and the EMR [electronic medical record] that she hadn't really met the patient 
nor recognized how 'knowing him' could affect care decisions.

But, as faculty members and leaders, we all bear responsibility for having created educational programs that do not put the value of being a personal physician at the heart of that education. If we lament the current situation, we have the responsibility, with younger colleagues and the next generations, to help change it. An encouraging study from North Carolina showed that residency practice redesign with a focus on increasing continuity with a personal physician showed a sustained increase of almost $50 \%$ from baseline. ${ }^{15}$ It can be done if we put our minds to it.

If we want to train the next generation to be personal physicians, we also need to examine the language we use and the structure of the education we shape. Should not we, for example, expect trainees to begin each presentation or note with a statement of who the patient is? For instance: "This 71-year-old, recently widowed and retired teacher who lives alone presents with ..." is more informative and patient centered than saying, "This 71year-old female presents with ...." The role of narrative in understanding and expressing the emotional and social component of a caring relationship helps learners understand and appreciate that the patient has a story, not just an objective history. The Veterans Administration initiated a patientdriven narrative, "My Life, My Story" which becomes part of a patient's medical record. ${ }^{16}$ Gayle Stephens once said that family medicine is that branch of medicine that requires knowing patients' names and being able to tell their stories. Knowing a person's story as they tell it and as we experience it over time enhances our understanding of the sociocultural factors in their world. Understanding social determinants of health begins with a deep understanding of the individuals and families for whom we care.

Should student clerkships be longitudinal rather than block time, particularly as blocks get smaller? Should faculty members team with individual residents to share their long-term patients? Such approaches might well improve opportunities for students and residents to develop meaningful relationships with patients over time and also with their faculty mentors. There have over the decades been repeated calls to change residency education to increase the time in continuity clinics and going to patients where they live and work. ${ }^{17}$ While education may be the hardest thing to change in any society, an effort by the American Medical Association may stimulate real reform of medical education that would create the conditions for students to learn what it means to be a personal physician. ${ }^{18}$ Good examples of successful longitudinal, integrated clerkships exist during which students are fully imbedded in rural and some urban community-based teaching practices for $\geq 9$ months. ${ }^{19-21}$ For over 45 years the Rural Physicians Associate Program (University of Minnesota) has had about 40 students per year learning and living in rural communities, being mentored by a family physician and an occasional rural general internist, while also having other surgical and medical experiences. Similar experiences at multiple other medical schools show that students selecting this option in medical school have a $>50 \%$ probability of choosing a career in family medicine and a rural practice. Not only do rural programs recruit students to family medicine but, once recruited, they stay in rural practice. ${ }^{22}$ Similar experiences with focused urban tracks show evidence of similar effects on career choice. ${ }^{23} \mathrm{We}$ believe the challenge for academic family medicine and internal medicine programs is to develop and enhance longitudinal training experiences for medical students and residents.

As we of the "older generation" have faced more serious and life-threatening illnesses, we have gained a personal appreciation for the positive impact of turning to our own personal physicians for diagnosis, care coordination, and follow-up care. Having faced sophisticated chemotherapy, transplantation, and complex surgery, we greatly appreciate the assistance of our personal physicians who know us and that of consultants in addressing these crises. We have felt the relief of seeing our personal physician come to the bedside during intensive hospital treatment to shape our care and to assist our family members who share our tears of anxiety or relief. Hope is essential during tough times, and it can arrive via the warm, knowing presence of a trusted personal physician. Not having that relationship can leave us frightened and anxious. As Bill Phillips said at the Keystone III meeting, "you can pretend to know, you can pretend to care, but you cannot pretend to be there."

For us, Keystone IV highlighted the priceless relationships that we have had. We need to struc- 
ture an educational system that values these relationships in an environment where learners experience their powerful effects on themselves and their patients. We need to model building trust over time, find the language to express it, and explore its challenges. We need to live how we want our students, residents, and colleagues to behave and not simply talk about it. We want to create the workforce our patients-and weneed.

Today, our system is in the midst of revolutionary change fostered by efforts to achieve value in health care. The climate is ripe for us as a profession and for us as individuals to negotiate what is best for our patients and for ourselves. But without substantive educational and health system reform, the ability to truly serve as personal physician and adhere to the values of continuity, responsibility, and accountability that are at the core of the work will continue to be threatened.

\section{References}

1. The Dartmouth atlas of health care. Lebanon, NH: The Dartmouth Institute for Health Policy and Clinical Practice; 2015. Available from: http:// www.dartmouthatlas.org/data/topic/. Accessed December 7, 2015.

2. Colwill JM. Narrative matters. A case of "medical homelessness". Health Aff (Millwood) 2010;29: 1067-70.

3. Friedberg MW, Van Busum KR, Aunon FM, et al. Factors affecting physician professional satisfaction and their implications for patient care, health systems, and health policy. Washington, DC: RAND Corporation; 2013. Available from: http:// www.rand.org/content/dam/rand/pubs/research reports/RR400/RR439/RAND_RR439.sum.pdf. Accessed December 4, 2015.

4. Shanafelt TD, Hasan O, Dyrbye LN, et al. Changes in burnout and satisfaction with work-life balance in physicians and the general US working population between 2011 and 2014. Mayo Clin Proc 2015;90: 1600-13.

5. Spinelli WM, Fernstrom KM, Britt H, Pratt R. "Seeing the patient is the joy": a focus group analysis of burnout in outpatient providers. Fam Med 2016; 48:273-8.

6. Rosser WW, Colwill JM, Kasperski J, Wilson L. Progress of Ontario's Family Health Team model: a patient-centered medical home. Ann Fam Med 2011; 9:165-71.

7. R-1 match reports - 2015. Ottawa, ON, Canada: Canadian Resident Matching Service (CaRMS); 2015. Available from: http://www.carms.ca/en/ data-and-reports/r-1/reports-2015/. Accessed April 22, 2016.

8. Reid RJ, Coleman K, Johnson EA, et al. The Group Health medical home at year two: cost savings, higher patient satisfaction, and less burnout for providers. Health Aff (Millwood) 2010;29:835-43.

9. Casalino LP, Pesko MF, Ryan AM, et al. Small primary care physician practices have low rates of preventable hospital admissions. Health Aff (Millwood) 2014;33:1680-8.

10. Mostashari F. The paradox of size: how small, independent practices can thrive in value-based care. Ann Fam Med 2016;14:5-7.

11. Bazemore A, Petterson S, Peterson LE, Phillips RL Jr. More comprehensive care among family physicians is associated with lower costs and fewer hospitalizations. Ann Fam Med 2015;13:206-13.

12. Kamerow D. Direct primary care: a new system for general practice. BMJ 2012;345:e4482.

13. Comprehensive primary care plus. Baltimore: U.S. Department of Health and Human Services, Centers for Medicare \& Medicaid Services; 2016. Available from: https://innovation.cms.gov/initiatives/ comprehensive-primary-care-plus. Accessed June 1, 2016.

14. Colwill JM, Cultice JM, Kruse RL. Will generalist physician supply meet demands of an increasing and aging population? Health Aff (Millwood) 2008;27: w232-41.

15. Weir SS, Page C, Newton WP. Continuity and access in an academic family medicine center. Fam Med 2016;48:100-7.

16. Cramer T. Veterans tell their stories. Washington, DC: Veterans Health Administration, U.S. Department of Veterans Affairs; 2014. Available from: http://www.va.gov/health/NewsFeatures/ 2014/March/Veterans-Tell-Their-Stories.asp. Accessed April 22, 2016.

17. Merenstein JH, Schulte JJ. A residency curriculum for the future. The STFM Task Force on Residency Curriculum for the Future. Fam Med 1990; 22:467-73.

18. Skochelak SE, Stack SJ. Creating the medical schools of the future. Acad Med 2016 Mar 22. [Epub ahead of print].

19. Zink T, Center B, Finstad D, et al. Efforts to graduate more primary care physicians and physicians who will practice in rural areas: examining outcomes from the University of Minnesota-Duluth and the Rural Physician Associate Program. Acad Med 2010;85:599-604.

20. Brooks KD, Eley DS, Zink T. Profiles of rural longitudinal integrated clerkship students: a descriptive study of six consecutive student cohorts. Med Teach 2014;36:148-54.

21. Norris TE, Schaad DC, DeWitt D, Ogur B, Hunt DD; Consortium of Longitudinal Integrated Clerkships. Longitudinal integrated clerkships for medical students: an innovation adopted by medical schools 
in Australia, Canada, South Africa, and the United States. Acad Med 2009;84:902-7.

22. Rabinowitz HK, Diamond JJ, Markham FW, Santana AJ. Retention of rural family physicians after 20-25 years: outcomes of a comprehensive medical school rural program. J Am Board Fam Med 2013; 26:24-7.

23. Haq C, Stearns M, Brill J, et al. Training in urban medicine and public health: TRIUMPH. Acad Med 2013;88:352-63. 